\title{
Call for Abstract Neurorad 2014
}

\section{Jahrestagung der Deutschen Gesellschaft für \\ Neuroradiologie e.V., 23.-25.Oktober 2014}

Sehr geehrte Kolleginnen und Kollegen,

im Namen der Deutschen Gesellschaft für Neuroradiologie laden wir Sie sehr herzlich zur Einreichung Ihres Abstracts auf der 49. Jahrestagung der DGNR in Köln ein.

Sie können Ihre Arbeiten zu diesen Themen einreichen:

- Neuroonkologie

- Multimodale Bildgebungskonzepte

- Pädiatrische Neuroradiologie

- Schädelbasis

- Spinalkanal

- Update Neurointervention

Bereichern Sie die 49. Jahrestagung der Deutschen Gesellschaft für Neuroradiologie und stellen Sie Ihre aktuellen Forschungsergebnisse in Form von Vorträgen

und Postern einem exzellenten Publikum vor. Sie können Ihre Arbeiten zu den oben ausgeführten Themen unter www.neurorad.de einreichen. Die Einreichung von wissenschaftlichen Beiträgen ist vom 21. März bis 22. Juni 2014 möglich. Alle angenommenen Beiträge werden in Clinical Neuroradiology veröffentlicht.

Wir freuen uns über Ihren Beitrag!

Mit kollegialen Grüßen

Prof. Dr. Ulrike Erneman

Kongresspräsidentin 2014

Prof. Dr. Michael Knauth

Präsident der DGNR

www.neurorad.de
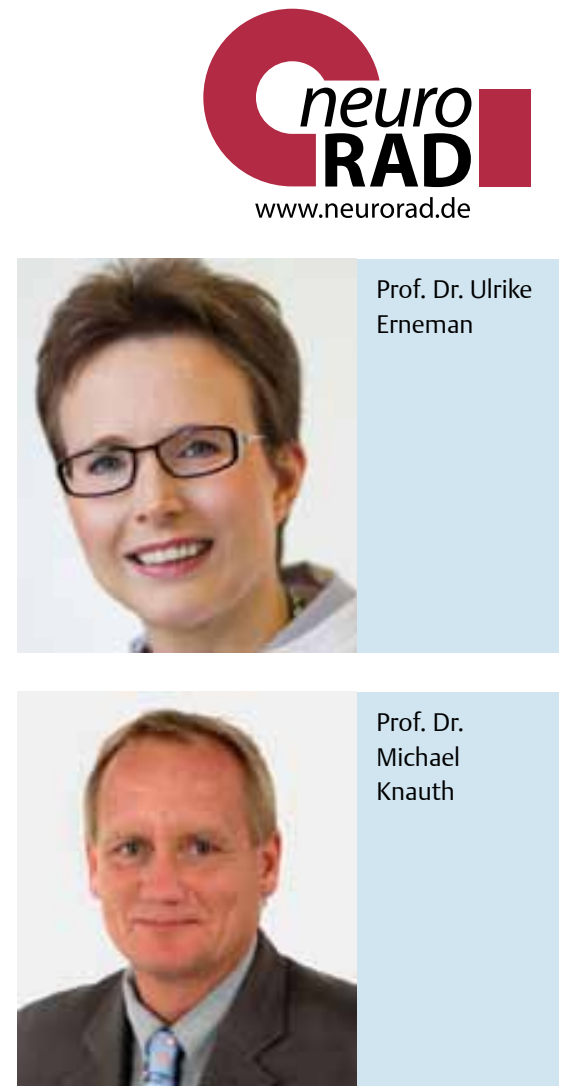